\title{
CORRELATIONAL ANALYSIS OF POLLUTANT EMISSION INTENSITY IN VARIOUS CONDITIONS OF OPERATION OF THE AUTOMOTIVE INTERNAL COMBUSTION ENGINE
}

\author{
Zdzisław CHŁOPEK ${ }^{1}$, Jacek BIEDRZYCKI ${ }^{2}$, Jakub LASOCKI ${ }^{3 *}$, Piotr WÓJCIK ${ }^{4}$ \\ ${ }^{1}$ Dept of Scientific Activities, Automotive Industry Institute, Warsaw, Poland \\ ${ }^{2,4}$ Engine and Chassis Laboratory, Automotive Industry Institute, Warsaw, Poland \\ ${ }^{3}$ Faculty of Automotive and Construction Machinery Engineering, \\ Warsaw University of Technology, Warsaw, Poland
}

Received 9 September 2016; revised 17 May 2017, 11 June 2017; accepted 7 September 2017

\begin{abstract}
The aim of this article was to analyse the correlation of emission intensity of carbon monoxide, hydrocarbons, nitrogen oxides, and carbon dioxide in various conditions of operation of the automotive internal combustion engine. The operational properties of the engine were investigated on chassis dynamometer in driving test cycles simulating various real-world conditions of the vehicle drive: street congestions, urban traffic without congestions, extra-urban traffic, and high-speed traffic. The correlational dependence of the pollutant emission intensity on the non-negative effective power of the engine and the correlational interdependence between the emission intensity of individual pollutants were investigated. The coefficients of Pearson's linear correlation, Spearman's rank correlation, Kruskal's gamma correlation, and Kendall's tau correlation were calculated. It was found that the emission intensity of pollutants in the driving test cycles strongly depends on the dynamic states of operation of the engine. The time histories of the emission intensity of pollutants were strongly correlated with the non-negative effective power of the engine. There were only a few cases where this correlation can be assessed as weak. The time histories of the emission intensity of individual pollutants were also strongly correlated with each other, with only a few exemptions.
\end{abstract}

Keywords: motor vehicle, internal combustion engine, pollutant emission, correlational analysis, driving test cycle, dynamic state.

\section{Introduction}

The Internal Combustion (IC) engines of motor vehicles operate predominantly in dynamic states (Chłopek 1999). Therefore, the works aimed at improving the operational properties of IC engines must include the testing of the engines in dynamic states corresponding to the conditions of typical engine operation in a moving vehicle.

The conditions corresponding to the operation of IC engines in moving vehicles are characterized by the process frequency range of the order of $0.1 \ldots 10 \mathrm{~Hz}$. The main process, which determines the state of operation of an automotive engine, is the vehicle speed (Chłopek 1999). Hence, automotive engines are often tested in motor vehicles subjected to vehicle driving test cycles on chassis dynamometers. In the case of engines of heavy motor vehicles, engine test benches are used (chiefly due to limited availability of adequate test equipment), where the conditions of engine operation in a moving vehicle are simulated.

For motor cars, many types of vehicle driving test cycles simulating vehicle drives in various traffic conditions have been developed. An important group of such tests consists of those used in type-approval procedures (Delphi Technologies 2016). Apart from the type-approval tests, many test cycles have been developed to obtain as accurate time-domain simulation of vehicle drives as possible. To determine the specific distance pollutant emissions and specific distance fuel consumption in the software developed by INFRAS (2018), an extensive family of motor car drive simulation tests has been prepared, which covers a very wide range of traffic conditions, from street congestions to high-speed (motorway) traffic (BAFU 2010). Within the implementation of the

*Corresponding author. E-mail: jakub.lasocki@pw.edu.pl 
European Artemis program (https://artemis-ia.eu), a system of Common Artemis Driving Cycles has been prepared, which consists of test cycles that simulate motor car drives in various traffic conditions (André et al. 2009; Barlow et al. 2009; Delphi Technologies 2016). Another example of vehicle driving test cycles is the system of test cycles developed at a French National Institute for Transport and Safety Research (Institut national de recherche sur les transports et leur sécurité - INRETS) (Nollet et al. 2000; Delphi Technologies 2016).

Many articles contain results of car testing in various driving cycles. The work of Favre et al. (2013) concerns investigation on pollutant emission from engines of passenger cars used in various driving cycles. The publication of Tutuianu et al. (2015) is devoted to the development of driving cycles to test the operational properties of lightduty vehicles. The results of empirical studies show high sensitivity of vehicle operational properties to the driving conditions. Particularly strong is the sensitivity of pollutant emission to the working conditions of the motor vehicle, determined by the vehicle's motion. Furthermore, operational properties of electric cars are also investigated in various driving cycles (Chłopek 2012; Raslavičius et al. 2013).

At Automotive Industry Institute (Przemystowy Instytut MOToryzacji - PIMOT) in Warsaw, families of vehicle driving test cycles have been prepared, which simulate the conditions of motor car drives in street congestion, urban, extra-urban, and high-speed (motorway and fast road) traffic (Chłopek et al. 2013a, 2013b, 2014, 2015). The PIMOT tests are treated as realizations of stochastic processes that characterize the conditions of vehicle drives (Chłopek et al. 2013b).

Increasing interest in the properties of IC engines in dynamic states can be observed in the recent years. The issues of modelling the pollutant emissions from IC engines in the static and dynamic states have been addressed in publications (Ajtay, Weilenmann 2004; Ajtay 2005). Results of correlational investigations on the processes of pollutant emissions from IC engines in dynamic states have been presented in publications (Chłopek 2010; Chłopek, Piaseczny 2013; Chłopek, Szczepański 2013; Nobuyuki et al. 2013). The modelling of the processes taking place in IC engines in dynamic states is often utilized to steering of the engines (Del Re et al. 2010; Ezzeddinne et al. 2008).

For several recent decades, pollutant emissions have been considered one of the main criteria of assessment of the quality of IC engines. The aim of this article is to analyse the correlation of emission intensity of pollutants in various conditions of operation of the automotive IC engine. The operational properties of the IC engine were tested in conditions simulating the real engine operation in a moving vehicle with respect to the dependence of the pollutant emission intensity on the current engine operation states characterized by non-negative effective power of the engine and with respect to the interdependence between the emission intensity of individual pollutants.

\section{Materials and methods}

The necessary empirical data was collected during traction tests of a passenger car under real-road driving conditions. These data were needed to simulate those conditions on the vehicle chassis dynamometer and then (on the basis of real-road data) to determine pollutant emission from an IC engine of the car tested (Chłopek et al. 2013a, 2014, 2015).

Road tests of vehicle were carried out in Masovian Voivodeship and Łódź Voivodeship in Poland. Urban traffic testing was conducted in Warsaw and Łódź, while non-urban - on the south-west exit routes from Warsaw and on the new section of the A2 motorway between Warsaw and Stryków.

The driving style has been adapted to most of the other road users.

A passenger car with a spark-ignition engine was used as the test object. Its basic characteristic is presented in Table.

Table. Specifications of passenger car used in tests

\begin{tabular}{|l|l|}
\hline Original equipment manufacturer & \multicolumn{1}{c|}{ Honda } \\
\hline Type & EJ9 \\
\hline Trade name & Civic 3D 1.4i \\
\hline Engine displacement & $1396 \mathrm{~cm}^{3}$ \\
\hline Engine type & $\mathrm{D} 14 \mathrm{Z1}$ \\
\hline $\begin{array}{l}\text { Number and } \\
\text { arrangement of cylinders }\end{array}$ & $\begin{array}{l}4, \\
\text { in-line }\end{array}$ \\
\hline Fuel system & $\begin{array}{l}\text { indirect, } \\
\text { multipoint injection }\end{array}$ \\
\hline Gearbox & $\begin{array}{l}\text { manual: } \\
5 \text { gears forward, } \\
1 \text { gear reverse }\end{array}$ \\
\hline
\end{tabular}

The tests were performed using Automex AMX530 OBDII/EOBD scanner, which is a universal reader of information from On-Board Diagnostics (OBD) system of vehicles. When installed in the Data Link Connector (DLC) port, the scanner allows real-time recording of engine parameters and other information provided by the vehicle manufacturer. AMX530 was used to record the following parameters during road tests: IC engine crankshaft speed, vehicle speed, engine steering.

The position of the car was also recorded during the measurements. For real-time positioning, the device Racelogic Performance Box, based on Global Positioning System (GPS) technology, was used. The data obtained was recorded in real time on a mobile computer.

The results of the traction tests of a passenger car under real-road conditions were divided into the following categories: street congestions, urban traffic without congestions, extra-urban (rural) traffic, high-speed traffic (on motorways and fast roads). Under those individual traffic conditions, the following numbers of vehicle speed samples were collected: 19 for street congestions, 34 for urban traffic without congestions, 16 for extra-urban traffic, 8 for high-speed traffic. 
Recorded samples of vehicle speed (speed vs. time curves) were treated as stochastic processes and subjected to the analysis in time, frequency and process value domains. Selected characteristics of the samples, including extreme values, mean value, variance, median and quadratic deviation were determined. The dependency of power spectral density of speed on frequency was also determined. There was a significant similarity of power spectral density of speed for the individual realizations of the investigated processes belonging to the particular category of traffic.

It has been found that the investigated processes are characterized by varying probability density. Statistical distributions are mostly asymmetrical. Some parameters show considerable variations, e.g. skewness (from -3.2 to 1.9 ) and kurtosis (from -1.5 to 13.1).

Based on the results of empirical tests of vehicle under real-road conditions, driving test cycles (PIMOT tests) for modelling of passenger car driving have been proposed. PIMOT tests were treated as stochastic processes having the form of the sets of vehicle speed realizations simulating traffic in the following conditions: street congestions (denoted by "CT"), urban traffic without congestions (denoted by "UT"), extra-urban (rural) traffic (denoted by "RT"), high-speed traffic (on motorways and fast roads, denoted by "HT").

The individual realizations of PIMOT tests, that modelled the assumed traffic conditions, were determined in accordance with the principle of faithful simulation in the time domain. As the criteria of similarity between the tests and actual traffic conditions, zero-dimensional characteristics of speed processes were compared: in the first place the mean value and standard deviation, and in the second place the median and quartile deviation.

Figures 1-4 present the final version of PIMOT tests four realizations for each individual stochastic process that correspond to the specific traffic model.

Figure 5 shows the average vehicle speed in all PIMOT tests.

Further information on the development of PIMOT tests and detailed results of the investigation on their statistical properties are presented in the other article by Chłopek et al. (2013b). For the purposes of this study, only CT1, UT1, RT1 and HT1 tests were used to evaluate the correlation of pollutant emission intensity in various conditions of operation of the IC engine. Figures 6-9 show the vehicle speed vs. time curves in these tests.

The average vehicle speed in individual tests (CT1, UT1, RT1, HT1) as well as the average value $A V$ and the standard deviation $\mathrm{D}$ of the average vehicle speed in those tests have been shown in Figure 10. The significant diversity in the average vehicle speeds in individual tests indicates that the conditions of operation of an automotive engine and, in consequence, the states of engine operation are also diverse to a considerable degree. The minimum value of the average vehicle speeds in the CT1 test is $8.5 \mathrm{~km} / \mathrm{h}$, while the maximum value of the average

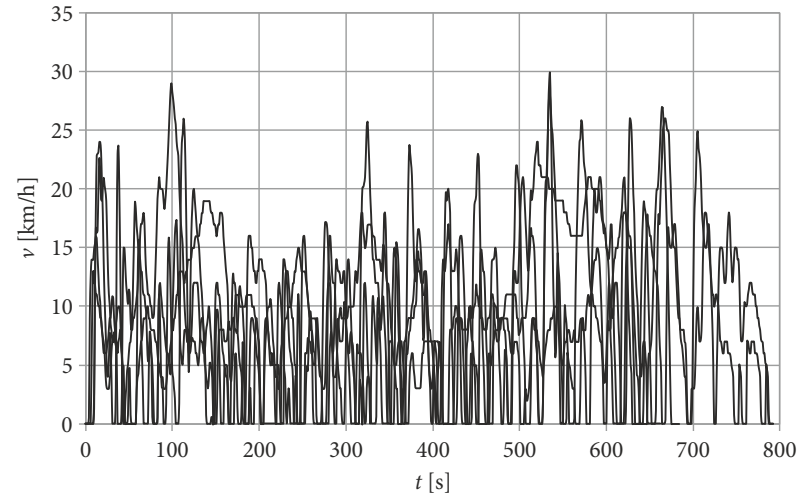

Figure 1. CT test (stochastic process of vehicle speed) for street congestions

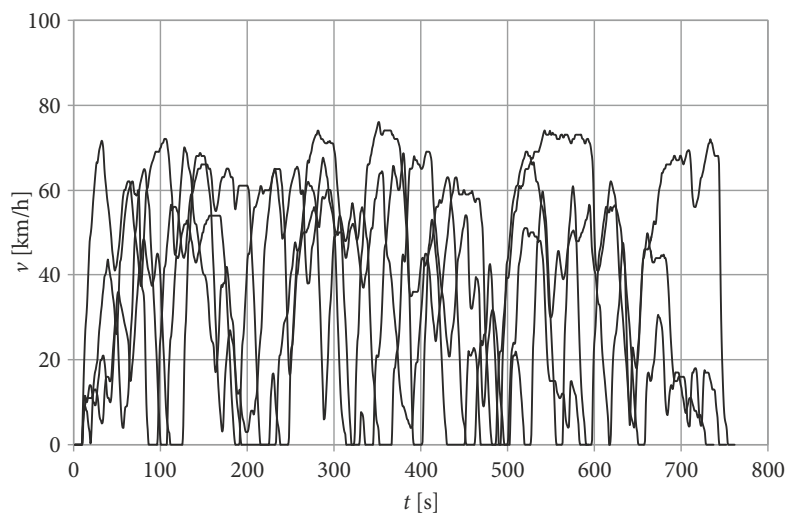

Figure 2. UT test (stochastic process of vehicle speed) for urban traffic without congestions

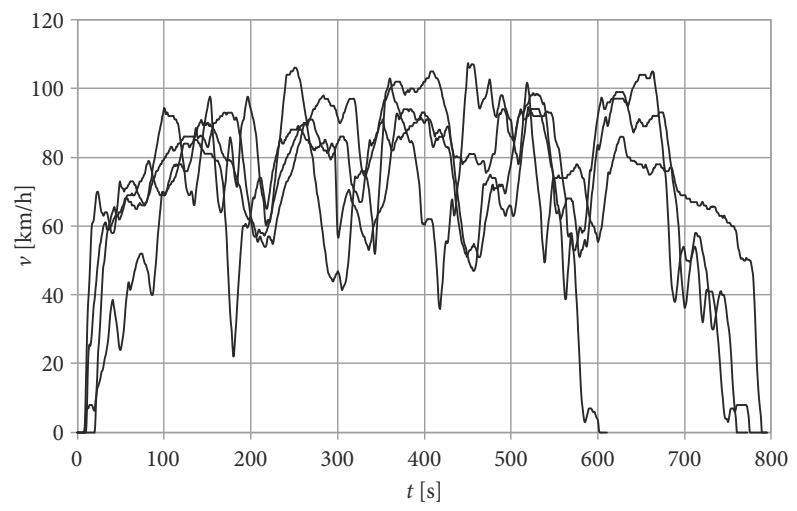

Figure 3. RT test (stochastic process of vehicle speed) for extra-urban (rural) traffic

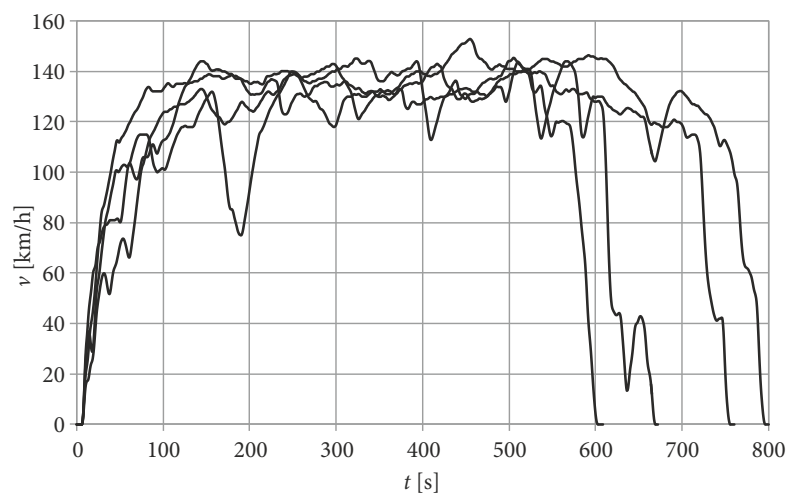

Figure 4. HT test (stochastic process of vehicle speed) for motorways and fast roads 
vehicle speeds in the HT1 test is $118.9 \mathrm{~km} / \mathrm{h}$. The total average value of the average vehicle speeds in all the tests is $58.4 \mathrm{~km} / \mathrm{h}$, with the coefficient of variation being 0.81 .

The car was tested on a vehicle chassis dynamometer Schenk Komeg EMDY 48. To examine the pollutant emissions, an exhaust gas analysing test stand was used, which incorporated a Horiba Mexa 7200 system provided with Horiba analysers to measure the concentrations of carbon monoxide (AIA-721A), hydrocarbons (FIA-725A), nitrogen oxides (CLA-755A), carbon dioxide (AIA-722), and oxygen (MPA-720). The details of the emission testing are presented in other publications by Chłopek et al. (2013a, 2014, 2015).

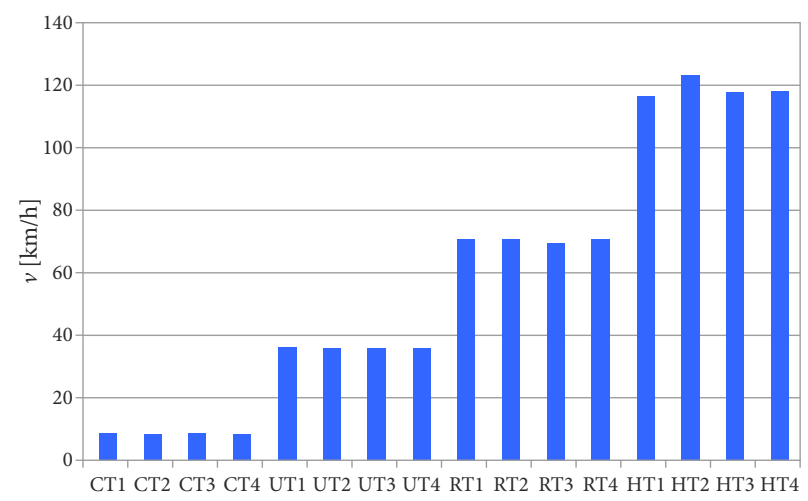

Figure 5. Average vehicle speed in individual realizations of PIMOT tests

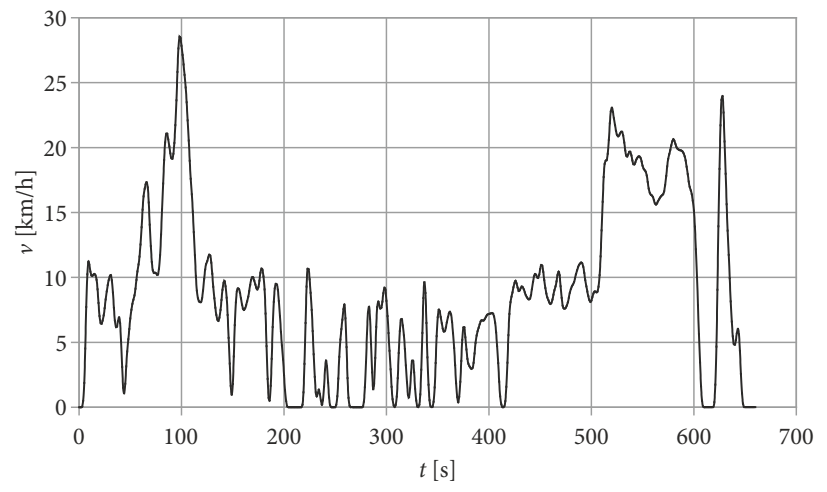

Figure 6 . Vehicle speed $v$ vs. time $t$ curve in the CT1 test

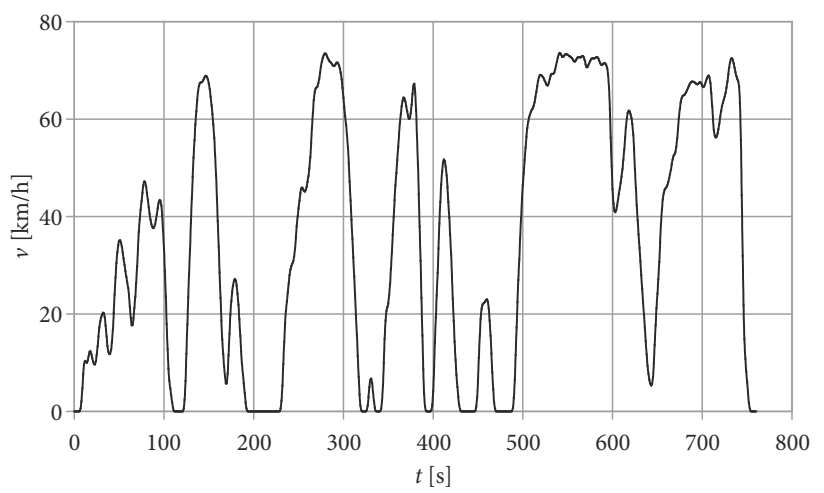

Figure 7. Vehicle speed $v$ vs. time $t$ curve in the UT1 test
During the experiments the values of, inter alia, the following quantities sampled with a frequency of $1 \mathrm{~Hz}$ and averaged from 10 measurements were recorded: vehicle speed, effective power of the IC engine, IC engine crankshaft speed, IC engine torque output, carbon monoxide, hydrocarbons, nitrogen oxides, and carbon dioxide emission intensity, fuel flow intensity.

The signals recorded were subjected to data processing. The gross errors were identified by the method of analysing the current variance of measurement results. The signals were subjected to low-pass filtration with the use of a Savitzky-Golay filter (Savitzky, Golay 1964), where both-side approximation from four data points on each side to a polynomial of degree 2 was applied.

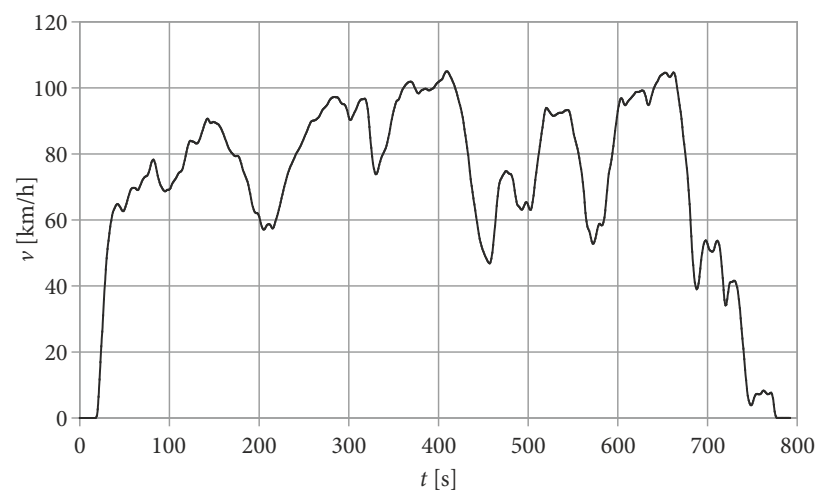

Figure 8 . Vehicle speed $v$ vs. time $t$ curve in the RT1 test

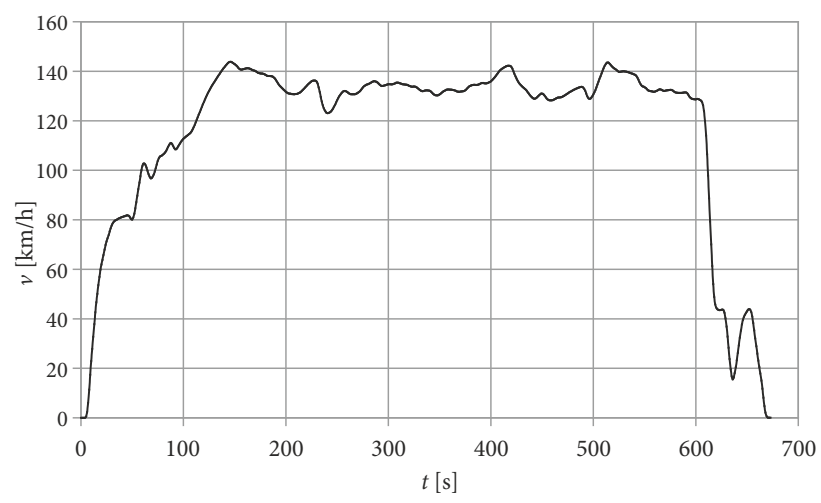

Figure 9. Vehicle speed $v$ vs. time $t$ curve in the HT1 test

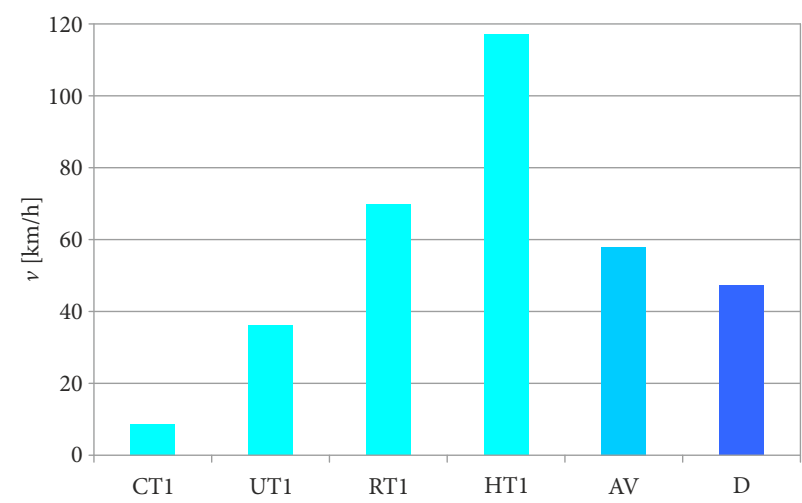

Figure 10. Average vehicle speed $v_{A V}$ in individual tests (CT1, $\mathrm{UT} 1, \mathrm{RT} 1, \mathrm{HT} 1$ ) as well as the average value $A V$ and the standard deviation $D$ of the average vehicle speed in all the tests 


\section{Results and discussion}

Emission intensities of carbon monoxide, hydrocarbons, nitrogen oxides and carbon dioxide were determined for all the tests. As an example, time histories of emission intensity of pollutants in the CT1 test have been shown in Figures 11-14.

Considering time histories of two different parameters, e.g. pollutant emission intensity and effective power of the engine, it is possible to assess similarity between them. The criteria of similarity can be various and concern the present values, the probability of occurrence of the individual values, frequency of their changes, etc. The correlation coefficients are single numbers informing about the link between the two parameters. All such coefficients operate on the same principle, but with different ways of modifying the value scale of the parameters. The information gained through the analysis of correlation coefficients can in some way prove a mutual relationship between the two courses, but do not represent the knowledge on this, which could be interpreted unambiguously. Because of the theoretical ambiguity of the assessment of the existence or non-existence of relationship (correlation) between the examined engine operational parameters, time histories there are significance tests used to verify the relevance of statistical hypotheses. It is possible then to define the basic hypothesis, for example, stating

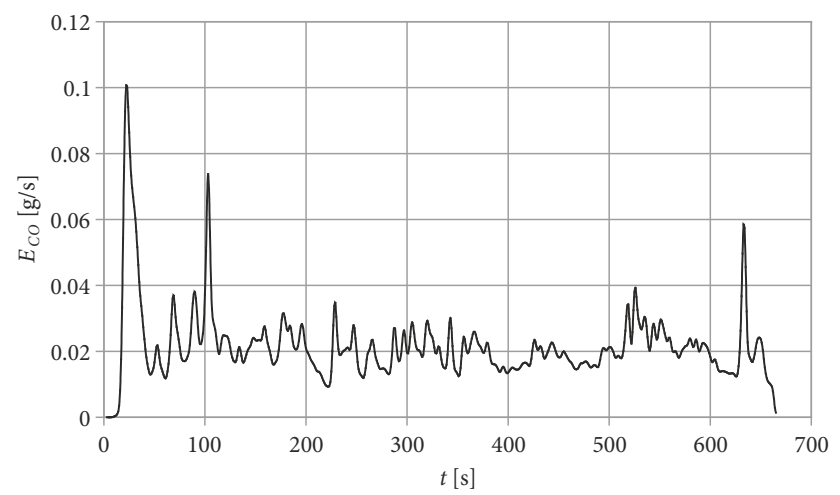

Figure 11. Time history of the carbon monoxide emission intensity $E_{C O}$ in the CT1 test

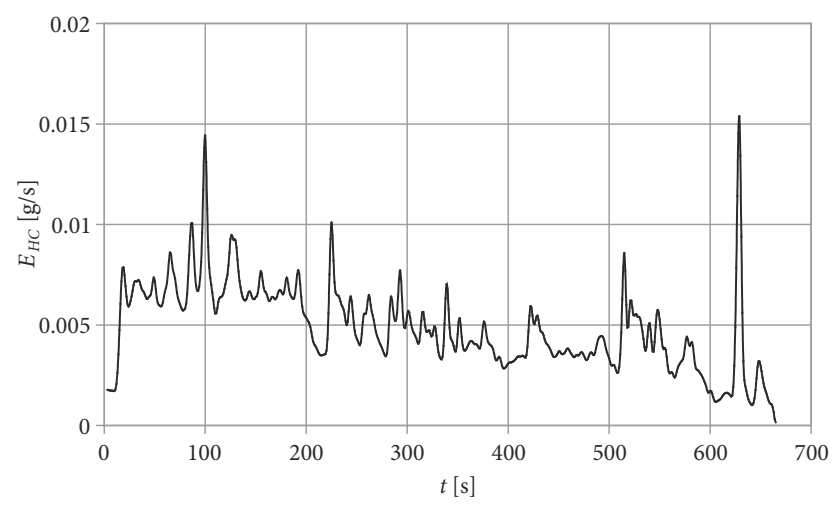

Figure 12. Time history of the hydrocarbons emission intensity $E_{C H}$ in the CT1 test no existence of correlation and the alternative hypothesis (Chłopek 2010; Chłopek, Piaseczny 2013; Chłopek, Szczepański 2013).

The correlational dependence of the pollutant emission intensity on the non-negative effective power of the engine and the correlational interdependence between the emission intensity of individual pollutants were investigated. For this purpose, the coefficients of Pearson's linear correlation (Pearson 1904), Spearman's rank correlation (Spearman 1904), Kruskal's gamma correlation (Kruskal, Wallis 1952), and Kendall's tau correlation (Kendall 1938) were calculated.

Results of the calculation of the above coefficients for the pollutant emission intensity and the non-negative effective power of the engine in individual tests have been presented in Figures 15-18.

Most of the sets of pollutant emission intensity were strongly correlated with the set of values of the non-negative effective power of the engine, to such an extent that the probability that the hypothesis of absence of Pearson's linear correlation would not be rejected was at a level of below 0.02 . Only in the cases of the hydrocarbons emission intensity in the HT test and the carbon monoxide emission intensity in the CT test, the probability that the hypothesis of absence of the correlation would not be rejected was at a level of more than 0.35 and more than 0.05 , respectively.

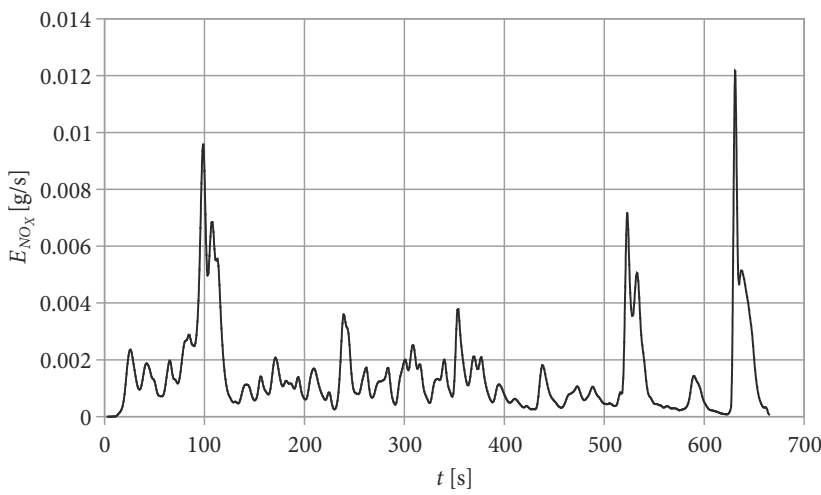

Figure 13. Time history of the nitrogen oxides emission intensity $E_{\mathrm{NO}_{\mathrm{X}}}$ in the CT1 test

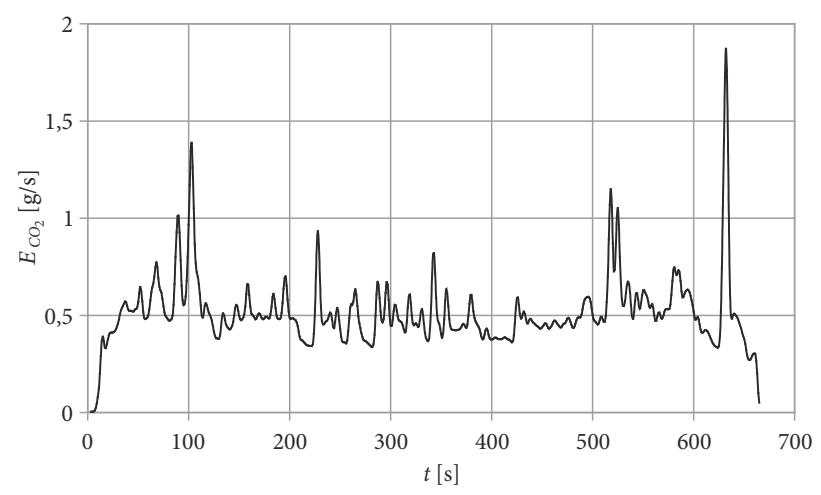

Figure 14. Time history of the carbon dioxide emission intensity $\mathrm{E}_{\mathrm{CO}_{2}}$ in the CT1 test 


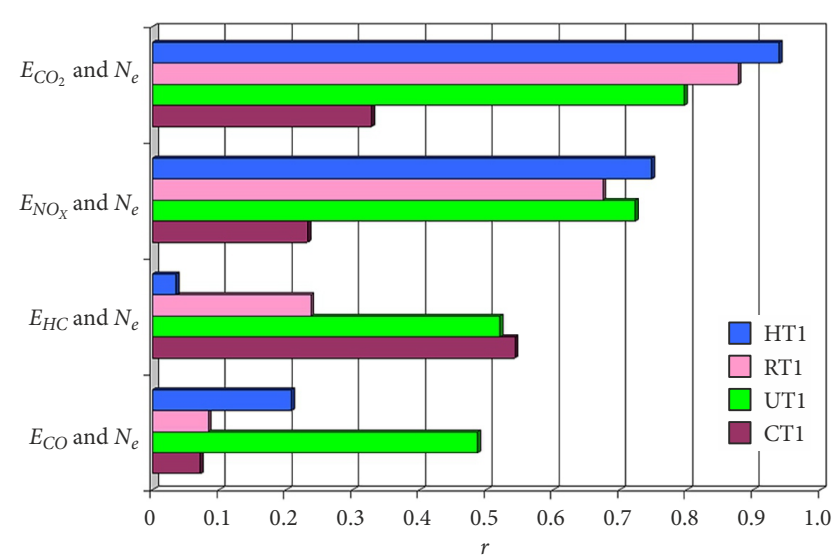

Figure 15. Coefficient of Pearson's linear correlation $r$ between the pollutant emission intensity $\left(E_{\mathrm{CO}_{2}}, E_{\mathrm{NO}_{X}}, E_{\mathrm{CH}}, E_{\mathrm{CO}}\right)$ and the non-negative effective power of the engine $N_{e}$ in individual tests (CT1, UT1, RT1, HT1)

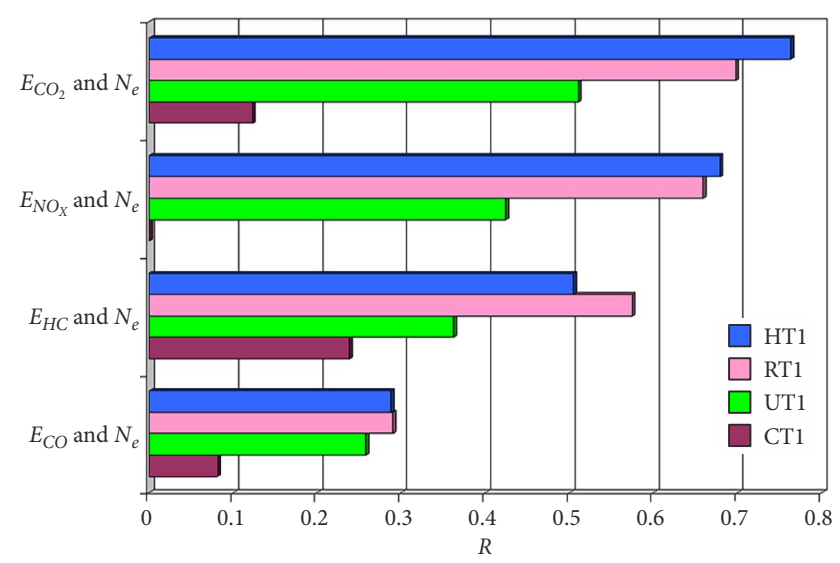

Figure 16. Coefficient of Spearman's rank correlation $R$ between the pollutant emission intensity $\left(E_{\mathrm{CO}_{2}}, E_{\mathrm{NO}_{X}}, E_{\mathrm{CH}}, E_{\mathrm{CO}}\right)$ and the non-negative effective power $N_{e}$ of the engine in individual tests (CT1, UT1, RT1, HT1)

A definite majority of the sets of pollutant emission intensity were strongly correlated with the set of values of the non-negative effective power of the engine, to such an extent that the probability that the hypothesis of absence of Spearman's rank correlation, Kruskal's gamma correlation, and Kendall's tau correlation would not be rejected was at a level of below 0.01 . Only in the case of the nitrogen oxides emission intensity in the CT test, the probability that the hypothesis of absence of any of the above correlation types would not be rejected was at a level of more than 0.95. In most cases, the lowest and the highest values of the coefficients of correlation were obtained for the CT test and HT test, respectively.

The coefficients of Pearson's linear correlation, Spearman's rank correlation, Kruskal's gamma correlation, and Kendall's tau correlation between the emission intensity of individual pollutants in specific tests have been presented in Figures 19-22.

A definite majority of the sets of emission intensity of individual pollutants were strongly correlated with each other, to such an extent that the probability that the

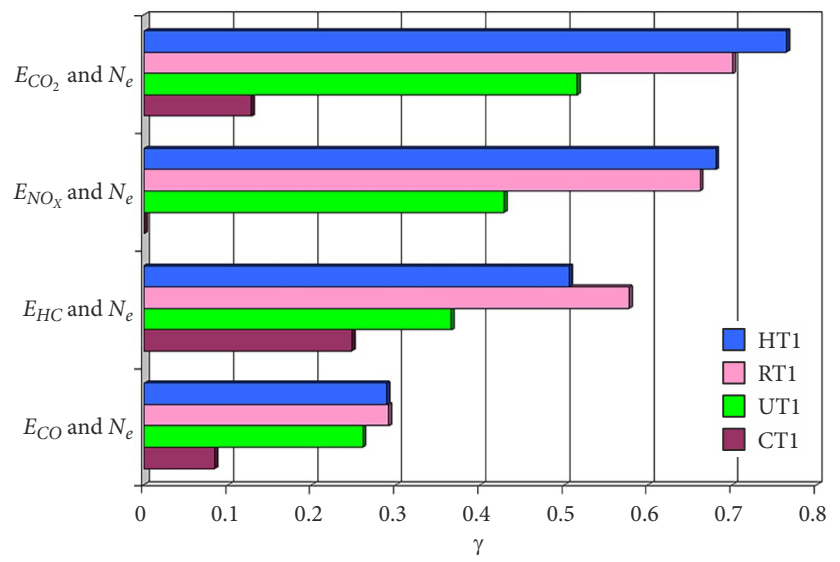

Figure 17. Coefficient of Kruskal's gamma correlation $\gamma$ between the pollutant emission intensity $\left(E_{\mathrm{CO}_{2}}, E_{\mathrm{NO}_{\mathrm{X}}}, E_{\mathrm{CH}}, E_{\mathrm{CO}}\right)$ and the non-negative effective power $N_{e}$ in individual tests (CT1, UT1, RT1, HT1)

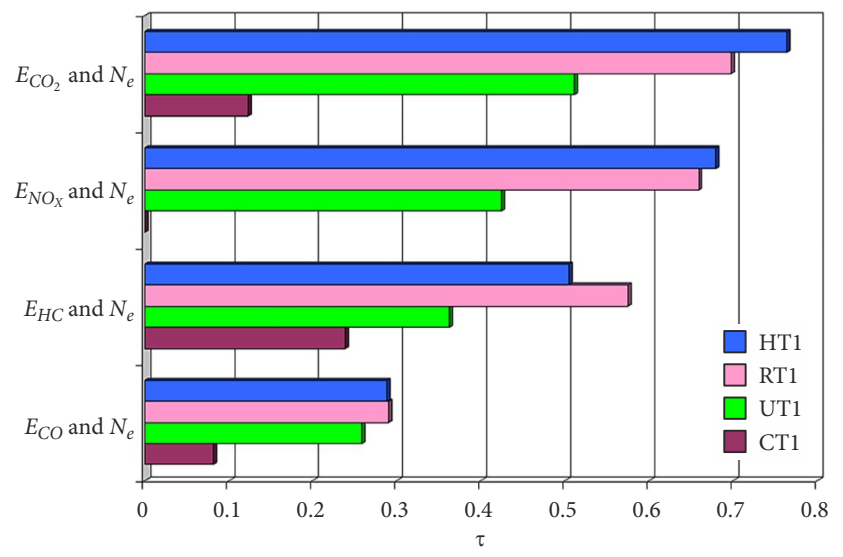

Figure 18. Coefficient of Kendall's tau correlation $\tau$ between the pollutant emission intensity $\left(E_{\mathrm{CO}_{2}}, E_{\mathrm{NO}_{\mathrm{X}}}, E_{\mathrm{CH}}, E_{\mathrm{CO}}\right)$

and the non-negative effective power $N_{e}$ in individual tests (CT1, UT1, RT1, HT1)

hypothesis of absence of a correlation would not be rejected was at a level of below 0.01. Only in the case of the carbon monoxide emission intensity and the carbon dioxide emission intensity in the HT test, the probability that the hypothesis of absence of any of the above correlation types would not be rejected was at a level of more than 0.13 . Hence, an opinion should be formulated that in general, the emission intensity of individual pollutants are strongly correlated with each other in diverse IC engine operation states determined by diverse conditions of vehicle motion. In most cases, the lowest and the highest values of the coefficients of correlation were obtained for the CT test and HT test, respectively.

The results of correlation analysis between operational parameters of IC engines often carry important cognitive information on their performance characteristics. However, there are some limitations of this approach. In the case of the correlation, the causal relationship is postulated (Chłopek, Szczepański 2013), although in fact sometimes it is difficult to determine which parameter can be considered as the cause, and which as the effect. 
It should also be noted that the correlation coefficient value depends not only on the existence of the link between two parameters, but also on the value of the courses investigated and of their length (multiplicity of the discrete time samples) (Chłopek, Szczepański 2013). Therefore, the interpretation of the magnitude of the result is a very relative matter. For this reason, it is necessary to verify the relevance of statistical hypotheses of no existence of correlation and the alternative hypothesis.

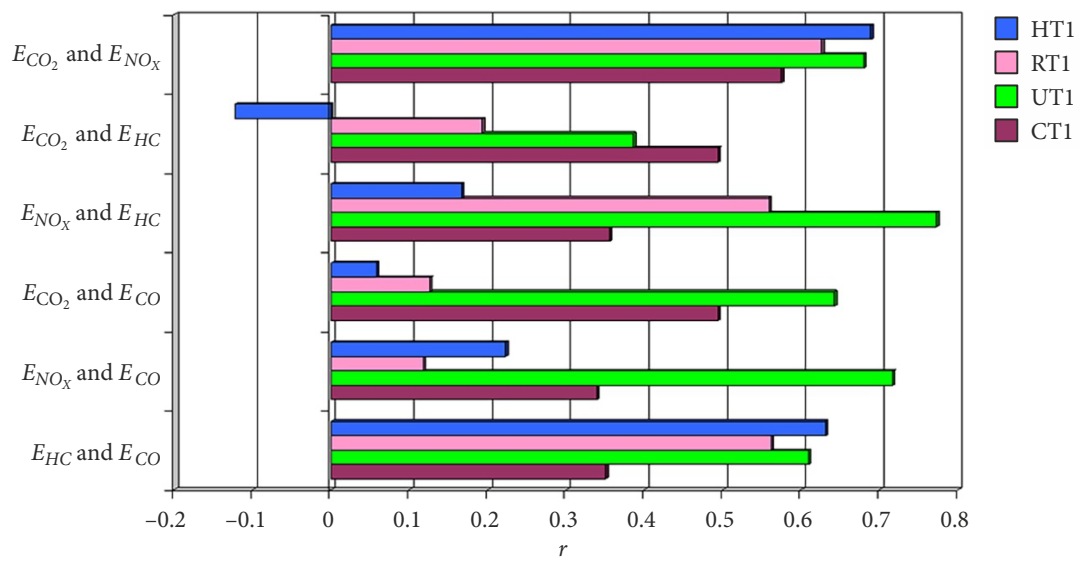

Figure 19. Coefficient of Pearson's linear correlation $r$ between the emission intensity of specific pollutants $\left(E_{\mathrm{CO}_{2}}, E_{\mathrm{NO}_{X}}, E_{\mathrm{CH}}, E_{\mathrm{CO}}\right)$ in individual tests (CT1, UT1, RT1, HT1)

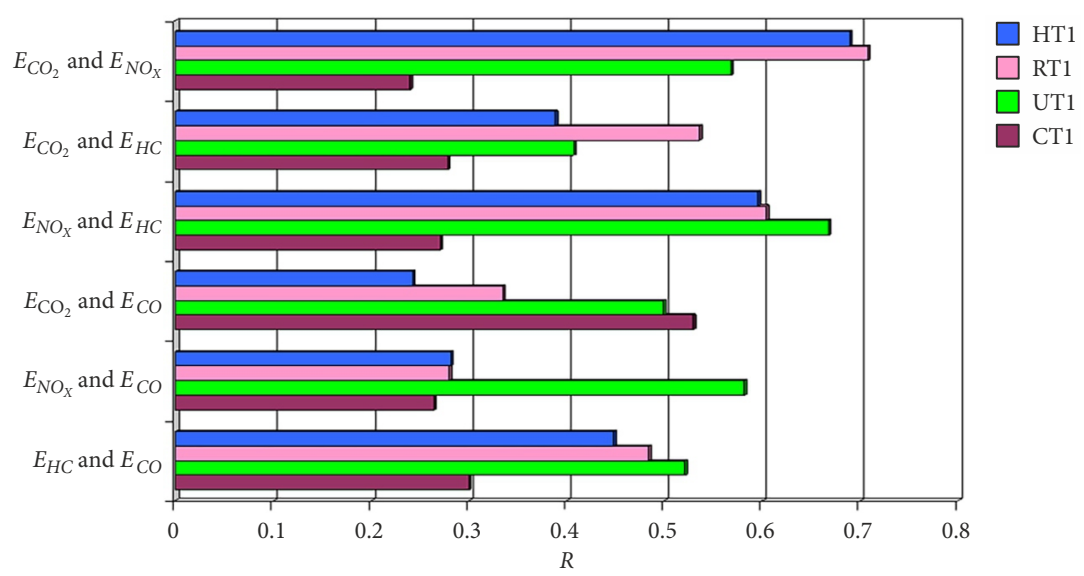

Figure 20. Coefficient of Spearman's rank correlation $R$ between the emission intensity of specific pollutants $\left(E_{\mathrm{CO}_{2}}, E_{\mathrm{NO}_{\mathrm{X}}}, E_{\mathrm{CH}}, E_{\mathrm{CO}}\right)$ in individual tests (CT1, UT1, RT1, HT1)

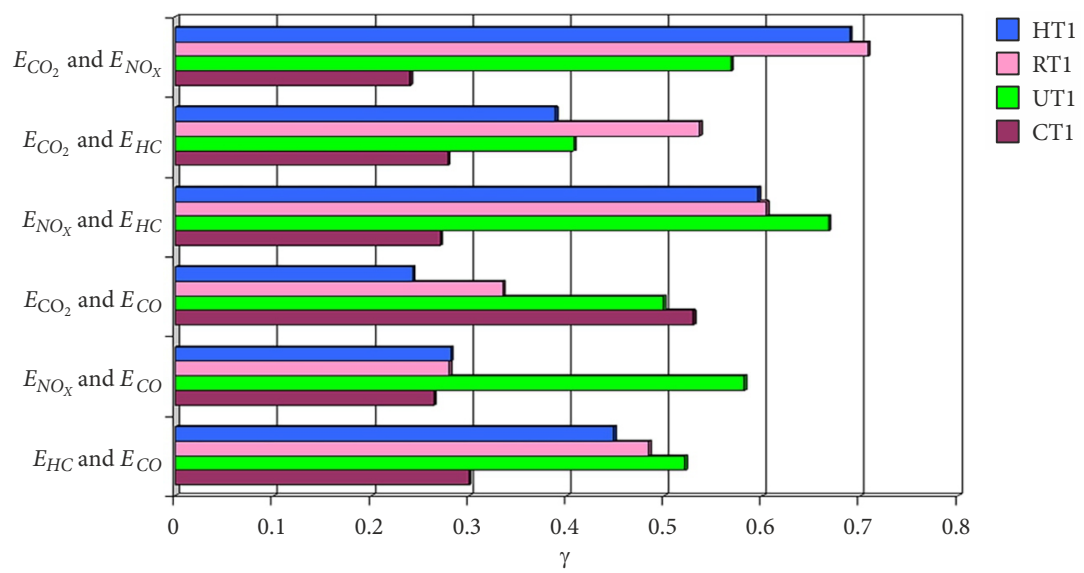

Figure 21. Coefficient of Kruskal's gamma correlation $\gamma$ between the emission intensity of specific pollutants $\left(E_{\mathrm{CO}_{2}}, E_{\mathrm{NO}_{X}}, E_{\mathrm{CH}}, E_{\mathrm{CO}}\right)$ in individual tests (CT1, UT1, RT1, HT1) 


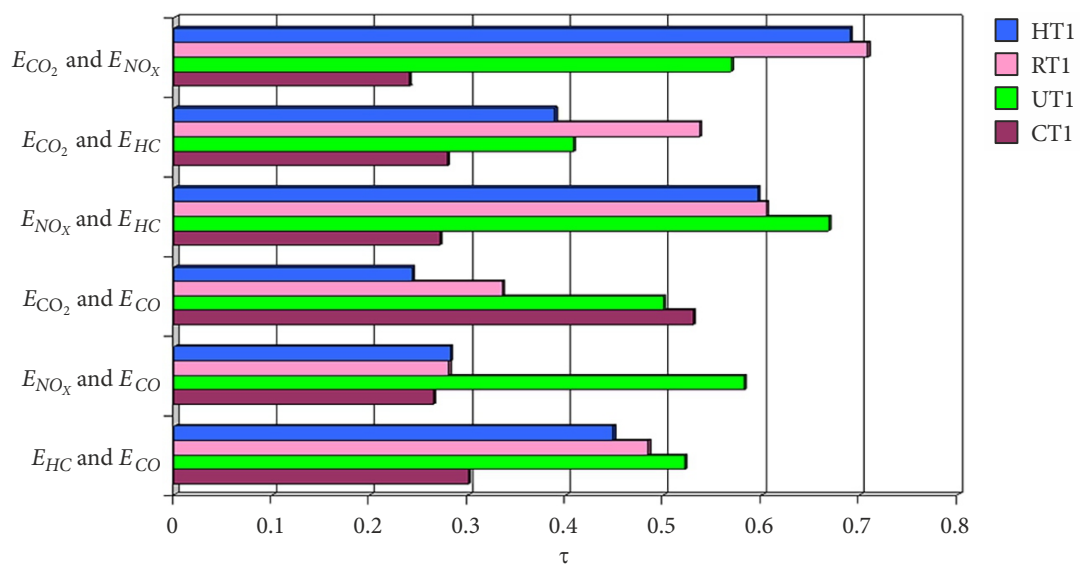

Figure 22. Coefficient of Kendall's tau correlation $\tau$ between the emission intensity of specific pollutants $\left(E_{\mathrm{CO}_{2}}, E_{\mathrm{NO}_{\mathrm{X}}}, E_{\mathrm{CH}}, E_{\mathrm{CO}}\right)$ in individual tests (CT1, UT1, RT1, HT1)

\section{Conclusions}

In result of the tests carried out, the following conclusions may be formulated:

- the emission intensity of pollutants in the driving test cycles strongly depends on time, which indicates that the emission intensity of pollutants depends on the dynamic states of operation of the automotive engine in the driving test cycles;

- the time histories of the emission intensity of pollutants have been found to be strongly correlated with the non-negative effective power of the engine, to such an extent that the probability that the hypothesis of absence of Spearman's rank correlation, Kruskal's gamma correlation, and Kendall's tau correlation would not be rejected was at a level of below 0.01 . There were only a few cases where this correlation can be assessed as weak;

- the time histories of the emission intensity of individual pollutants have been found to be strongly correlated with each other, to such an extent that the probability that the hypothesis of absence of a correlation would not be rejected was at a level of below 0.01 . Only in the case of the carbon monoxide emission intensity and the carbon dioxide emission intensity in the HT test, the probability that the hypothesis of absence of any correlation would not be rejected was at a level of more than 0.13. In most cases, the lowest and the highest values of the coefficients of correlation were obtained for the CT test and HT test, respectively.

Contemporary environmental priorities justify the continued pursuit of research into the determinants of pollutant emissions from automotive combustion engines. It is expedient, in the first place, to conduct further research involving larger number of cars, with different properties. The authors have particularly high expectations in the planned investigation of pollutant emission from car engines in terms of their actual use with the Portable Emissions Measurement System (PEMS) (Andersson et al. 2014). It is also planned by the authors to present the results of investigations of the dependence of pollutant emission from IC engines on engine operating conditions in the domains of: spectral analysis and probability distribution (Chłopek 1999).

\section{Funding}

This work was supported by the National Science Centre of Poland (Grant No N509556440) and the Automotive Industry Institute (Poland).

\section{Contribution}

All of the authors participated in analysis and interpretation of data.

Moreover, Zdzisław Chłopek drafted the article; Jacek Biedrzycki provided conception and design of the experimental work; Jakub Lasocki took part in acquisition and processing of data, and prepared the article for submission to the Journal; Piotr Wójcik took part in acquisition and processing of data.

\section{Disclosure statement}

Authors declare that they do not have any competing financial, professional, or personal interests from other parties.

\section{References}

Ajtay, D. 2005. Modal Pollutant Emissions Model of Diesel and Gasoline Engines. Doctoral Dissertation. Swiss Federal Institute of Technology in Zurich, Switzerland. $124 \mathrm{p}$. https://doi.org/10.3929/ethz-a-005163854

Ajtay, D.; Weilenmann, M. 2004. Static and dynamic instantaneous emission modelling, International Journal of Environment and Pollution 22(3): 226-239. https://doi.org/10.1504/IJEP.2004.005534

Andersson, J.; May, J.; Favre, C.; Bosteels, D.; De Vries, S.; Heaney, M.; Keenan, M.; Mansell, J. 2014. On-road and chassis dynamometer evaluations of emissions from two Euro 6 diesel vehicles, SAE International Journal of Fuels and Lubricants 7(3): 919-934. https://doi.org/10.4271/2014-01-2826 
André, M.; Keller, M.; Sjödin, Å.; Gadrat, M.; McCrae, I.; Dilara, P. 2009. The Artemis European tools for estimating the transport pollutant emissions, in Proceedings of the 18th Annual International Emission Inventory Conference "Comprehensive Inventories - Leveraging Technology and Resources", 14-17 April 2009, Baltimore, Maryland, US, 1-10.

Barlow, T. J.; Latham, S.; McCrae, I. S.; Boutler, P. G. 2009. A Reference Book of Driving Cycles for Use in the Measurement of Road Vehicle Emissions. Version 3. TRL Limited. 284 p. Available from Internet: https://assets.publishing.service.gov.uk/government/uploads/system/uploads/attachment_data/file/4247/ ppr-354.pdf

BAFU. 2010. Luftschadstoff-Emissionen des Strassenverkehrs 1990-2035. Bundesamt für Umwelt (BAFU), Schweiz. 130 S. Available from Internet: https://www.bafu.admin.ch/bafu/ de/home/themen/luft/publikationen-studien/publikationen/ luftschadstoff-emissionen-des-strassenverkehrs-1990-2035. html (in German).

Chłopek, Z. 1999. Modelowanie procesów emisji spalin w warunkach eksploatacji trakcyjnej silników spalinowych, in Prace Naukowe Politechniki Warszawskiej. Mechanika 173: 3-193 (in Polish).

Chłopek, Z. 2010. A correlation analysis of the pollutant emission from a self ignition engine, Combustion Engines (1): 25-31.

Chłopek, Z. 2012. Research on energy consumption by an electric automotive vehicle, The Archives of Automotive Engineering - Archiwum Motoryzacji (3): 19-31.

Chłopek, Z.; Biedrzycki, J.; Lasocki, J.; Wójcik, P. 2013a. Investigation of pollutant emissions from a motor vehicle engine in tests simulating real vehicle use in road traffic conditions, Combustion Engines (3): 202-207.

Chłopek, Z.; Biedrzycki, J.; Lasocki, J.; Wójcik, P. 2013b. Investigation of the motion of motor vehicles in Polish conditions, The Archives of Automotive Engineering - Archiwum Motoryzacji 60(2): 3-20.

Chłopek, Z.; Biedrzycki, J.; Lasocki, J.; Wójcik, P. 2015. Assessment of the impact of dynamic states of an internal combustion engine on its operational properties, Eksploatacja $i$ Niezawodnosc - Maintenance and Reliability 17(1): 35-41. https://doi.org/10.17531/ein.2015.1.5

Chłopek, Z.; Biedrzycki, J.; Lasocki, J.; Wójcik, P. 2014. Examination of pollutant emissions and fuel consumption at tests simulating the real conditions of operation of a passenger car, The Archives of Automotive Engineering - Archiwum Motoryzacji 65(3): 3-18.

Chłopek, Z.; Piaseczny, L. 2013. Badania korelacyjne emisji zanieczyszczeń z silnika okrętowego znajdującego się w stanach dynamicznych, in V International Congress on Combustion Engines, 24-26 June 2013, Bielsko-Biała, Poland. (in Polish).

Chłopek, Z.; Szczepański, T. 2013. Correlation studies of combustion engines properties in dynamic states, Combustion Engines (3): 175-182.

Del Re, L.; Allgöwer, F.; Glielmo, L.; Guardiola, C.; Kolmanovsky, I. (Eds.). 2010. Automotive Model Predictive Control: Models, Methods and Applications. Springer-Verlag London. 290 p. https://doi.org/10.1007/978-1-84996-071-7

Delphi Technologies. 2016. 2016/2017 Worldwide Emission Standards: Passenger Cars and Light Duty. 104 p. Available from Internet: https://www.delphi.com/sites/default/files/inline-files/delphi-worldwide-emissions-standards-passengercars-light-duty-2016-7.pdf
Ezzeddinne, M.; Castro, E.; Lengellé, R. 2008. Dynamic design of experiments for engine pollutants emissions modeling and optimization, SAE Technical Paper 2008-01-2454. https://doi.org/10.4271/2008-01-2454

Favre, C.; Bosteels, D.; May, J. 2013. Exhaust emissions from European market-available passenger cars evaluated on various drive cycles, SAE Technical Paper 2013-24-0154. https://doi.org/10.4271/2013-24-0154

INFRAS. 2018. The Handbook Emission Factors for Road Transport (HBEFA). Version 4.1. INFRAS, Switzerland.

Kendall, M. G. 1938. A new measure of rank correlation, Biometrika 30(1/2): 81-93. https://doi.org/10.2307/2332226

Kruskal, W. H.; Wallis, W. A. 1952. Use of ranks in one-criterion variance analysis, Journal of the American Statistical Association 47(260): 583-621. https://doi.org/10.2307/2280779

Nobuyuki, S.; Baumann, W.; Ropke, K.; Knaak, M. 2013. Transient modeling of diesel engine emissions, International Journal of Automotive Engineering 4(3): 63-68. http://doi.org/10.20485/jsaeijae.4.3_63

Nollet, V.; Schadkowski, C.; Hue, S.; Flandrin, Y.; Dechaux, J.-C. 2000. Elaboration d'un cadastre d'émissions de polluants primaires dans la région Nord-Pas-de-Calais. Les transports automobiles, Pollution Atmosphérique 165: 109-119 (in French). Available from Internet: http://lodel.irevues.inist.fr/pollutionatmospherique/docannexe/file/3009/109_nollet.pdf

Pearson, K. 1904. On the Theory of Contingency and its Relation to Association and Normal Correlation. Dulau and Co. 35 p.

Raslavičius, L.; Starevičius, M.; Keršys, A.; Pilkauskas, K.; Vilkauskas, A. 2013. Performance of an all-electric vehicle under UN ECE R101 test conditions: a feasibility study for the city of Kaunas, Lithuania, Lithuania, Energy 55: 436-448. https:// doi.org/10.1016/j.energy.2013.03.050

Savitzky, A.; Golay, M. J. E. 1964. Smoothing and differentiation of data by simplified least squares procedures, Analytical Chemistry 36(8): 1627-1639. https://doi.org/10.1021/ac60214a047

Spearman, C. 1904. The proof and measurement of association between two things, The American Journal of Psychology 15(1): 72-101. https://doi.org/10.2307/1412159

Tutuianu, M.; Bonnel, P.; Ciuffo, B.; Haniu, T.; Ichikawa, N.; Marotta, A.; Pavlovic, J.; Steven, H. 2015. Development of the world-wide harmonized light duty test cycle (WLTC) and a possible pathway for its introduction in the European legislation, Transportation Research Part D: Transport and Environment 40: 61-75. https://doi.org/10.1016/j.trd.2015.07.011 